\title{
Integrated Design Approach for Housing the Urban Poor: The Case of Pakistan
}

\author{
SHAKEEL QURESHI \\ Virginia Polytechnic Institute and State University \\ USA
}

\begin{abstract}
Success of a housing program depends on compatibility of its housing provision with the needs, resources, and priorities of the target group. This is especially true for housing programs in developing countries, which often do not reach the urban poor. This paper argues that the main reason for their failure is the design approach that is used to develop them. The paper addresses two major questions: What is the framework that explains the success or failure of different housing programs? and, What design approach should architects adopt, and the role they should play, so as to reach the urban poor? Different households have different needs, resources, and priorities in various aspects of housing. The conventional design approach addresses only a few aspects and produces incompatible housing. An integrated design approach, on the other hand, addresses all related aspects of housing and achieves compatibility. The Khuda-ki-Basti incremental development scheme in Hyderabad, Pakistan demonstrates that compatible housing can reach the urban poor. To produce compatible housing, the conventional approach needs to be modified to an integrated approach. This, in turn, requires broadening the architects' role and changing the focus of architectural education in the arena of housing for the urban poor.
\end{abstract}

\section{THE DILEMMA}

The problem of housing the urban poor in developing countries is overwhelming and ever-increasing. 'While it has several dimensions both at the policy formation level and at the policy implementation level, this paper addresses the problems encountered at the policy implementation level only. Governments generally carry out national housing policy in the form of housing programs. The dilemma is that housing programs for the urban poor in developing countries, so far, have failed to reach their target groups. Most of the housing stock, developed through these programs, is takenover by upper income groups (Gilbert 1992). Various theorists and policy makers believe that housing affordability for target groups is the main reason for the problem (Burgess 1992). Other reasons highlighted in the literature are: lack of political will (Mathey 1992); unavailability of land, fi- nances, and other resources (Gilbert 1992); and poor project administration (Van der Linden 1994). However, any one or any combination of these factors fails to provide a framework that can explain the success or failure of different housing programs. ${ }^{2}$

Housing programs have failed despite attention to these reasons. For instance, several programs have focused on the problem of affordability. To make housing affordable to the urban poor, governments have heavily subsidized public housing, and provided housing units on affordable installments--sometimes almost free of charge (Gilbert 1992). However, shortly after the urban poor receive subsidized housing, they sell their units on the open market for profit instead of living in them. The households use the profit for their other priority needs (such as food, business, or dowry), and generally return to the informal or other housing in which they had previously been living. This results in the waste of scarce public resources. Therefore, housing programs fail even when affordability to the target group is not the reason. Attention to the other factors, mentioned above, also does not make housing programs successful. For example, in many sites-and-services projects (on undeveloped land): political will has been favorable; public agencies have made land available; governments have provided funds and personnel to administer programs; and development agencies have kept the costs of plots affordable to households. However, in spite of all this, most sites-and-services programs have failed to reach low-income groups. Often plots have remained unoccupied, resulting in deterioration of the physical infrastructure (Hassan 1992).

In contrast, most squatter upgrading programs have been successful in improving the condition of houses and infrastructure in squatter areas--this needs an explanation. These programs have succeeded in serving the urban poor, in spite of using significantly fewer financial and other public resources than do public housing and sites-and-services programs (Malik 1987, Van der Linden 1994).

\section{COMPATIBLE HOUSING}

This paper theorizes that the success of a housing program is 
a function of compatibility of 'housing provision' in the program with 'needs, resources, and priorities' of target groups. ${ }^{3}$ Perfect compatibility infers that housing provision is affordable, acceptable, and retainable by households. Affordability means that the household's paying capacity is compatible with the cost of the housing unit provided. Acceptability means that the household's priorities of needs are compatible with the provisions of the program. Similarly, retainability means that the household's investment in its housing unit is compatible with the housing unit's market value. If the market value of the unit is much higher than the household's investment (in cash and kind), then the household will be tempted to sell it for profit. The housing, therefore, will be vulnerable to upward filtration. So, 'affordability,' 'acceptability,' and 'retainability' are three indicators upon which compatibility of housing provision with needs, resources, and priorities of the target group can be assessed. A housing program which has perfect compatibility will be successful, while less-than-perfect compatibility reduces the chances for success of the program. If a provision is partially compatible (for example, affordable but not acceptable, and/or not retainable), then the program will not be fully successful. Therefore, success levels of various housing programs may be explained by comparing those programs with respect to compatibility of their housing provisions.

Affordability, acceptability, and retainability are defined by householder's needs, resources, and priorities in various

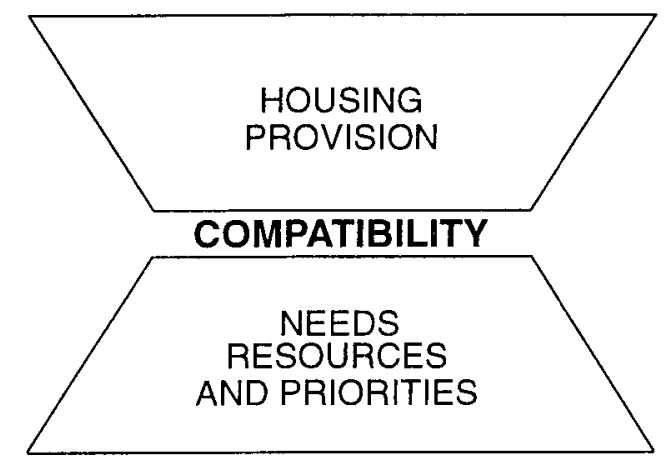

Fig. 1. Success of a Housing Program Depends on Compatibility

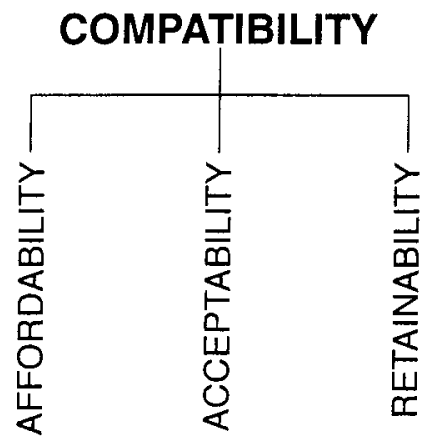

Fig. 2. Indicators of Compatibility

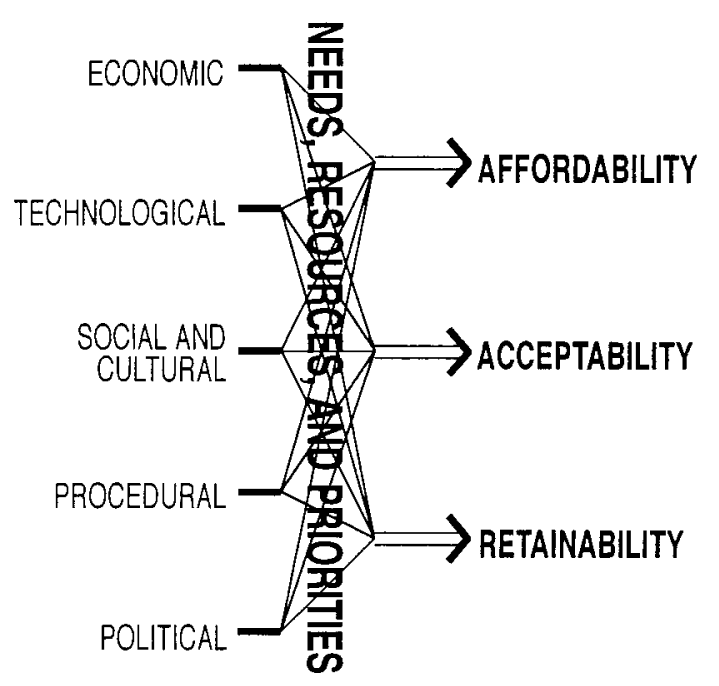

Fig. 3. Determinants of Affordability, Acceptability, and Retainability

aspects of housing. Different aspects of housing may be grouped under the headings of economic aspects, technological aspects, social and cultural aspects, procedural aspects, and political aspects. For each aspect, different households have different needs, resources, and priorities. This implies that affordability, for example, of two households belonging to the same income group will not necessarily be the same if their priorities are different.

Various agencies, erroneously, often determine affordability of households by using a fixed percentage of total household income. Government of Pakistan, for instance, assumes that about 18 percent of household income is spent on housing (Qureshi 1994,167). On the contrary, a household's decision about its spending on housing is based on the priorities that the household assigns to its various needs. For example, a household that identifies as its priority need the maintenance of a small neighborhood shop, will allocate much less than 18 percent of its income to housing. Another household of the same income group, whose priority need is to own a house, will be ready to spend considerably more than 18 percent for this purpose. In addition, the latter household will generate a substantial amount of money through various sources to pay for the cost of a new home. These sources may include the household's compulsory savings, sale of jewelry and other assets, and loans from relatives and friends. Similar to affordability, different households may have different criteria for acceptability of a housing provision. For example, acceptability for one household may be linked with the household's social need of staying close to its social group. For another household, however, the acceptability may depend on its economic need of being near an area where there are more job opportunities.

Thus, it is almost impossible to establish, without asking household members, the true determinants of affordability, 
acceptability, and retainability for different households. Because needs, resources, and priorities of the urban poor vary from one household to another, it is misleading to generalize them for the whole group.

\section{DESIGN APPROACH}

When decision-makers (politicians and bureaucrats) conceive a housing program, they broadly decide what to deliver. Their decision is influenced mainly by factors like political will, policy dictates, and availability of land, finances, and other resources (Ali and Mumtaz 1988). Once decision-makers decide 'what to deliver,' then the housing program is designed to define 'how to deliver.' It is not until this stage that the decision-makers involve architects and planners in the program, and together they determine a design approach. The term 'design approach,' here, is not used in the limited sense of architectural design of housing units. Rather, it is used in the broader sense of program design. While defining 'how to deliver,' a design approach also shapes and fine-tunes the nature and form of a housing provision. It is the most important tool that, if used properly, can make a housing provision compatible.

\section{FRAGMENTED DESIGN APPROACH}

The design approach, which is conventionally used for developing housing programs, is partial or fragmented. It addresses only a few aspects of housing and ignores or undermines all others. Most importantly, a fragmented design approach is not structured to accommodate the variable needs of different households. Architects, planners, and other technocrats, who are engaged in designing a housing program, choose only a few aspects as the foci of their approach. Generally, they focus on one or two of the following technological and economic aspects of housing (Mathey 1992; Qureshi 1994, Van der Linden 1994):

a) Reduction in the cost of housing-unit by minimizing plot sizes, reducing covered area, and curtailing building materials and labor;

b) Standardization and mass production of building components;

c) Reduction in the cost of the physical infrastructure;

d) Development of appropriate materials and construction techniques; and

e) Provision of loans and subsidies to the urban poor.

Selection of the aspects, which are emphasized in the conventional design approach, is often based on one or more of the following factors:

- Decision-makers specify beforehand, those particular aspects to architects and planners in the 'terms of contract';

- According to the architects' and planners' perception of the problem, only those aspects are relevant; or

- Architects' and planners' own expertise is limited to those aspects of housing.

Social, cultural, procedural, and political aspects of hous- ing are generally ignored. The aspects ignored in the design approach are later handled by the formal sector in a routine manner. The formal sector's routine way of handling aspects of housing are generally not compatible with the needs, resources, and priorities of the urban poor. For instance, 'order of activities' in the development of a housing scheme is a procedural aspect of housing. The order, which public agencies traditionally follow, starts with 'planning,' then 'servicing,' then 'building,' and finally 'occupying.' This order of activities serves the needs of upper-income groups, and not the poor. There is usually a gap of three to ten years from the time a housing scheme is planned to the time any household can occupy its housing unit (Hassan 1992, 273). Needs and priorities of the urban poor are quite the opposite as they have clearly, and repeatedly, demonstrated through the informal sector housing. Their preferred order of activities starts with 'occupying,' then 'building,' then 'servicing,' and finally 'planning' (Butt 1992, 15). The urban poor cannot wait for several years to fulfill their immediate need of occupying a housing unit or a piece of land. Therefore, imposing a procedure that is quite opposite to the needs, resources, and priorities of the target group reduces compatibility and, in turn, reduces the chances of success of the program.

A fragmented design approach, at best, achieves partial compatibility. So, by focusing on economic aspects, a housing provision may become affordable to the urban poor. However, by ignoring other aspects, the provision is likely to become not acceptable and/or not retainable to them. Consequently, the program will fail to reach the target group. Although there are several reasons why housing programs for the urban poor in developing countries have failed, one important reason is that these programs have been developed by using a fragmented design approach and are either incompatible or only partially compatible.

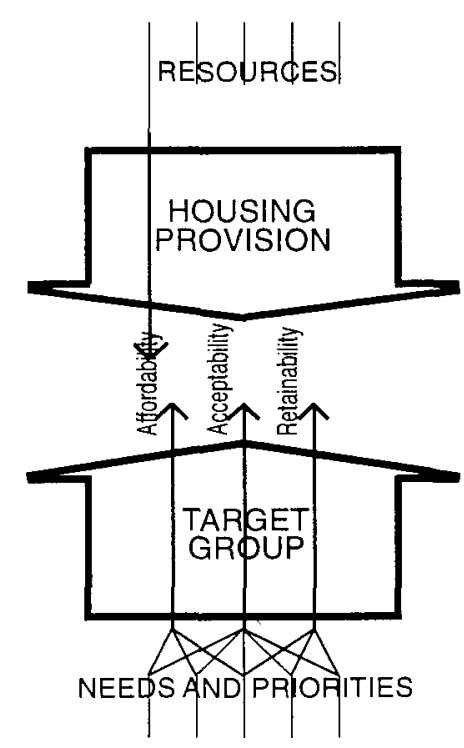

Fig. 4. Fragmented Design Approach Produces Incompatible Housing 


\section{INTEGRATED DESIGN APPROACH}

An integrated design approach places emphasis on three main strategies: first, on addressing all related aspects of housing; second, on accommodating variable needs, resources, and priorities of different households through their active involvement in the program; and third, on enabling households to develop their own compatible housing incrementally. Important steps of designing a housing program through this approach are:

1) Identify the target group;

2) Prepare initial design of the housing program. The initial design should be comprehensive enough to address all those aspects of housing that may affect affordability, acceptability, and retainability of the target group. It should, also, be flexible enough to allow for changes of any nature and extent as needed by households at any stage of the program;

3) Involve households and get their feedback on the design;

4) Modify the initial design based on feedback from households; and

5) Enable households to implement the housing program incrementally according to their needs, resources, and priorities.

To achieve the same objective, for instance, to make a housing provision affordable to the urban poor, the fragmented and integrated approaches use different strategies and emphases. For example, a fragmented design approach may focus only on technological aspects. These aspects, as mentioned in the previous section, may include reducing plot sizes, covered area, building materials, and labor. In an integrated design approach, however, all related aspects of housing (economic, technological, social and cultural, procedural, and political) are addressed simultaneously and integrated. Attention is paid not only to reducing the cost of housing, but also to increasing the paying capacity of households. Cost of housing may be reduced by: producing costefficient designs of housing area, physical infrastructure, and housing-units; using appropriate standards of planning; developing appropriate building materials and construction techniques; involving households in the design as well as implementation; and lending building materials and building components to the households. Concurrently, the paying capacity of households may be increased by: providing job opportunities to the households in the process of development; and allowing households to pay back their loans in kind (labor) instead of in cash. When different aspects of housing are integrated in a housing program, a planned action in one area or aspect triggers a complementary activity in another area or aspect of housing. The cumulative effect of many small gains in various aspects becomes significant. So, by making optimum use of all potential resources, an integrated design approach will be more successful than a fragmented approach in achieving the objective--to make the housing provision affordable to the target group.

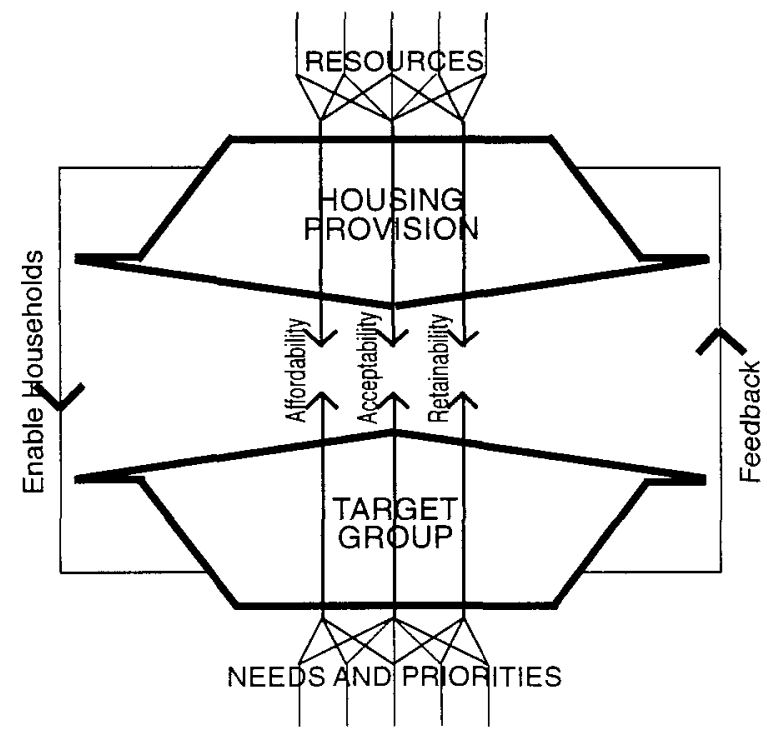

Fig. 5. Integrated Design Approach Produces Compatible Housing

Most squatter upgrading programs have been successful in improving the condition of houses and infrastructure in squatter areas. The reason is that, in squatter areas, households themselves have managed their housing according to their needs, resources, and priorities. In squatter upgrading programs, development agencies have been merely responding, because of the political pressure, to some needs of the households. These needs, which households cannot manage themselves, include tenure status and the physical infrastructure. Therefore, by default, they have been engaging in an integrated design approach.

\section{ARCHITECTS' ROLE}

The role of architects and planners in a fragmented design approach is significantly different from their role in an integrated approach. A fragmented approach is top-down, in which movement from one stage to another is linear. Each stage is dominated by one of the actors: bureaucrats, technocrats, developers, and households. Feedback has no, or negligible, affect on the course of project development. In this approach, there is almost no interaction between the architects and planners and the households. Households come into the picture very late, when they are offered a housing unit or a plot in the program on a 'take it or leave it' basis. The architects' and planners' role in the fragmented approach is limited to producing a design according to the requirements dictated by decision-makers. When the decision-makers approve the design, they hand it over to appropriate agencies for implementation. Once the implementation is underway, the role of the architects and planners is over.

An integrated design approach, on the other hand, is interactive and evolutionary. Movement from one stage to another is nonlinear--like a spiral. Loops in the spiral repre- 


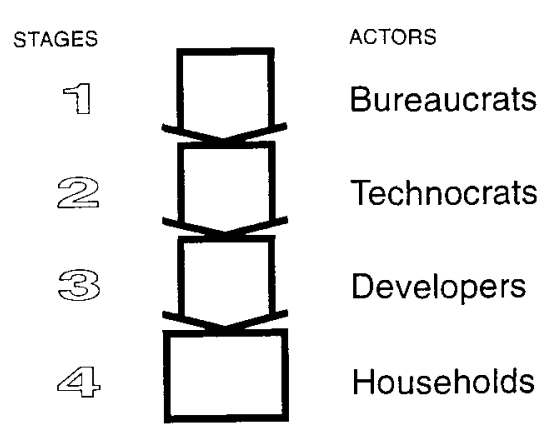

Fig. 6. Fragmented Approach is Top-Down

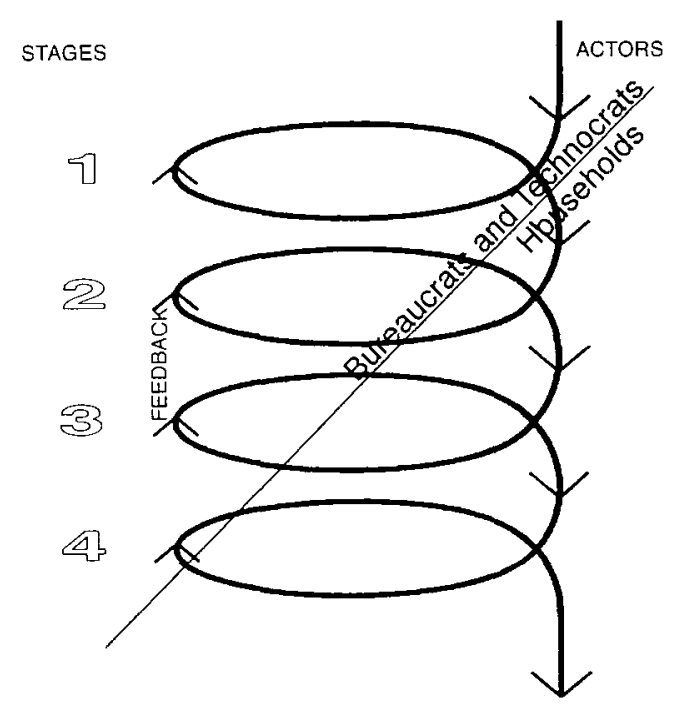

Fig. 7. Integrated Approach is Interactive and Evolutionary

sent different stages of the program. Backward movement in each loop indicates feedback. Design in each stage is modified on the basis of the feedback from households, before implementing it, and going on to the next stage. Several actors are involved in each stage of the program. Proportional involvement of various actors changes from one stage to another. Initial stages of the program are dominated by bureaucrats and technocrats. However, they gradually decrease their involvement, giving way to households, so that the implementation stages of the program are dominated by the households. In an integrated approach, households become the central figures. They hold the power of making final decisions in all matters related to their housing on the basis of their needs, resources, and priorities. The role of bureaucrats and technocrats in this approach is to enable the households to develop their own compatible housing.

As enablers and facilitators, the task of architects and planners is not only to design a housing program, but also to monitor its evolution over time. The initial design, which architects and planners prepare, provides tentative answers to the following questions for each aspect of housing: When and how will that aspect be addressed in the program? Who will be the actors? What will be their roles? and How will these different actors and procedures enable the households to develop their own compatible housing? The initial design, therefore, is not an end in itself. Rather, it is a means to an end. It is a starter or initiator of an interactive process. The design evolves and modifies continuously as the involvement of households increases. This evolutionary process keeps going because needs, resources, and priorities of households keep changing over time.

\section{AN EXAMPLE OF AN INTEGRATED DESIGN APPROACH}

Hyderabad is the fifth biggest city of Pakistan, with a present estimated population of 1.2 million. About 70 percent of households belong to low-income groups. The housing condition in the city is very poor. According to the housing census conducted by the Government of Pakistan in 1972, about 5,000 housing units had one room accommodating 10 to 14 persons, and about 35,000 had one room for six to nine persons. Between 1978 and 1985, Hyderabad Development Authority launched four housing schemes of sites and services for middle- and upper-income groups through the conventional design approach. However, by 1985 only 35 out of 15,000 plots were inhabited. The rest of them remained vacant. Not any of these schemes or any part of a scheme targeted low-income groups. The urban poor fulfilled their housing needs, mainly, through the informal sector. Around 25 percent of the total population of the city lives in informal housing (Van der Linden 1992; Siddiqui and Khan 1994).

Hyderabad Development Authority analyzed the limitations and potentials of both the formal and informal sectors, and decided to carry out an experiment. The approach adopted for the experiment not only incorporated the positive features of the informal sector, but also ensured to overcome its major limitations. Using this new approach in 1986, the Authority launched an incremental development scheme on 100 acres of state land, located 12 kilometers from Hyderabad. The scheme was later named 'Khuda-ki-Basti' (settlement of God) by those urban poor who benefited from it. In this scheme, the Authority provides unserviced plots, measuring 720 square feet each, to the urban poor on affordable installments and involving simple procedures. Initial services are limited to communal water supply and public transport to the city. Households acquire the remaining services incrementally. For this purpose, they contribute money and decide for themselves the types and levels of services required, according to their priorities (Siddiqui and Khan 1994). The Authority's role is to enable them to develop their compatible housing. Thus, important features of an integrated approach have been incorporated.

The scheme has shown substantial achievements in a short time span. Within one year of its announcement, 1,500 plots were inhabited. In three years, this number increased to around 3,000 . The scheme has been successful in reaching 
the urban poor, as many households belong to below the 10th percentile of the household-income distribution of the country (Van der Linden 1992). The inhabitants have developed the physical and social infrastructure without causing any financial burden to the government. Up to 1993, the households had collected and spent about five million rupees (approximately US $\$ 170,000$ ) on acquiring water supply, sewerage, and electrification. It enabled 86 percent of the houses to get indoor water connections and about 50 percent to have electricity. There are five primary schools, seven private health centers, 110 shops, and 247 carpet looms which provide jobs to about 600 persons (Siddiqui and Khan 1994). "This speed of development is considerably higher than that of informal settlements anywhere in Pakistan" (Hassan 1992, 298).

\section{CONCLUSION}

Compatibility of housing provision with needs, resources, and priorities of target groups is a framework that explains the success or failure of different housing programs. The most important tool for achieving compatibility is the design approach. So, the performance of a program greatly depends on the way the program is designed. It is more likely to achieve compatibility by using an integrated rather than a fragmented design approach. The more comprehensive and integrated the design approach is, the more compatible will be the housing provision. This concept of compatible housing calls for: a radical change in the conventional design approach; a broader role for architects and planners; and a new architectural education focus in the arena of housing for the urban poor.

The role of architects and planners in an integrated approach is broader and more demanding than in a fragmented approach. It demands more time, greater commitment, interaction with households, and the skill to coordinate various parts and actors of a housing program. Unfortunately, this is not the role for which architects and planners are trained in educational institutions. So, there is a need to change the focus of education in the fields of architecture and planning while studying housing for the urban poor in developing countries. Some desired emphases include: multiple dimensions of the problem of housing; social research; and importance of economic, social and cultural, procedural, and political aspect of housing, besides the technological aspects.

\section{NOTES}

I The term 'urban poor' is interchangeably used with 'target groups,' and 'low-income groups' representing the households who live in urban areas and have incomes below the median level in the national household-income distribution.

2 The author defines a 'successful housing program' for the urban poor, as one in which long-term end-users predominantly belong to low-income groups.

3 Turner is the leading advocate of enabling strategy and recommends to base it on needs, resources, and priorities of the urban poor (1992).

\section{REFERENCES}

Ali, Reza, and Babar Mumtaz. 1988. The Housing Question and Other Answers. Lahore, Pak.: National College of Arts.

Burgess, Rod. 1992. "Helping Some to Help Themselves: Third World Housing Policies and Development Strategies." Beyond Self-Help Housing. Ed. Kosta Mathey. London: Mansell Publishing Ltd. 75-91.

Butt, Arif Qayyum. 1992. "The Incompatibility Between the Needs of Low-Income Households and the Perception and Attitudes of Architects and Planners: A Case Study of Lahore, Pakistan." Diss. London: Development Planning Unit.

Gilbert, Alan. 1992. The Housing for the Urban Poor. Cities, Poverty and Development. Eds. Alan Gilbert and Josef Gugler. London: Oxford University Press. 114-154.

Hassan, Arif. 1992. Seven Reports on Housing. Karachi, Pak.: Orangi Pilot Project.

Malik, Rafiq A. 1987. "Low-Income Housing in Lahore: A Study of Serviced Sites and Incremental Housing Approach." Diss. Sheffield: University of Sheffield.

Mathey, Kosta. 1992. "Positions on Self-Help Housing." Beyond Self-Help Housing. Ed. Kosta Mathey. London: Mansell Publishing Ltd. 379-396.

Qureshi, Shakeel. 1994. "Housing for the Homeless in Pakistan: An Integrated Design Approach." Thesis. Lahore, Pak.: University of Engineering and Technology.

Siddiqui, Tasneem A. and M. Azhar Khan. 1994. "The Incremental Development Scheme." Third World Planning Review 16 (3): $277-291$.

Turner, John F.C. 1992. Foreword. Beyond Self-Help Housing. Ed. Kosta Mathey. London: Mansell Publishing Ltd. xi-xiv.

Van der Linden, Jan. 1992. "Back to the Roots: Key to Successful Implementation of Sites-and-Services." Beyond Self-Help Housing. Ed. Kosta Mathey. London: Mansell Publishing Ltd. 341-352.

---. 1994. "Where Do We Go From Here?" Editorial. Third World Planning Review 16 (3): 223-229. 